\title{
Expression of matrix metalloproteinase-9 and tumour necrosis factor-alpha in the synovial cells of patients with meniscus tears
}

\author{
R. Atiç', E. Deveci \\ ${ }^{1}$ Department of Orthopaedic Surgery, Faculty of Medicine, Dicle University, Diyarbakır, Turkey \\ ${ }^{2}$ Department of Histology and Embryology, Faculty of Medicine, Dicle University, Diyarbakır, Turkey \\ [Received: 12 September 2018; Accepted: 25 September 2018]
}

Background: A meniscus tear is a serious trauma that develops during swinging motion of the fixed foot. Meniscus tears may also be accompanied by divergence of the lateral ligaments of the knee joint.

Materials and methods: We enrolled 45 males and 35 females with meniscal tears in the present study. Patients with local joint pain, swelling, difficulty climbing stairs, patellar creeping, difficulties with daily living activities, local pain on palpation, and walking and running complaints, were included. We performed preoperative magnetic resonance imaging. Synovial fluid $(5 \mathrm{~mL}$ ) was aspirated from the lateral suprapatellar pouch of each knee with meniscal pain with the patient in the supine position. Blood samples were taken and biochemical parameters were analysed. The Harris haematoxylin and eosin staining protocol was used to evaluate tissue samples, and the levels of anti-matrix metalloproteinase (MMP)-9 and anti-tumour necrosis factor alpha (TNF- $\alpha$ ) antibodies were measured immunohistochemically. Results: Increased numbers of lymphocytes and neutrophils, hyperplastic erythrocytes, and fibroblasts were observed in the joint fluid of females. In males, the fibroblast cells were hyperplastic and plasma cell numbers were increased. MMP-9 expression was elevated in plasma cells, fibroblasts, and neutrophils; and TNF- $\alpha$ expression was observed in lymphocytes and polymorphic nucleated cells. We suggest that increased fluid levels in inflamed joints with meniscal tears, and the associated inflammation, disrupt the cartilage matrix and elevate the production of cytokines such as TNF- $\alpha$ and MMP-9 via release from cells such as fibroblasts that synthesise these mediators.

Conclusions: Anti-TNF- $\alpha$ treatment may prevent meniscal tears and prevent or slow the development of osteoarthritis. (Folia Morphol 2019; 78, 3: 535-544)

Key words: meniscus tear, synovial cells, matrix metalloproteinase 9, tumour necrosis factor alpha

\section{INTRODUCTION}

The meniscus is a fibrocartilage-like tissue consisting mainly of collagen and water in which cells reside. The meniscus stabilises the knee joint, absorbing snare forces. Good shock absorption and weight transmission are necessary to maintain normal anatomical function of the knee joint. The meniscus facilitates cartilage nutrition by pushing the synovial fluid toward the articular surface and protecting the synovial film layer that forms on that surface. Meniscal tears are common. Meniscus movement during index flexion prevents injury by improving the fit between joint faces. The posteromedial

Address for correspondence: E. Deveci, Professor, PhD, Dicle University, Faculty of Medicine, Department of Histology and Embryology, 21280, Diyarbakır, Turkey, tel: +90 412 2488001, ext. 4443 (faculty room), fax: +90 412 2488440, e-mail: devecie32@hotmail.com 
part of the meniscus is less mobile than other parts, explaining why tears are more often observed in this region [13]. Depending on the age, the meniscus tends to become more susceptible to lesions and tears caused by degenerative disease and trauma, leading to severe musculoskeletal disorders [11].

In young subjects, intact meniscal tissue may be ruptured by trauma; meniscal tearing often induces fluid accumulation, perceived as swelling and a sense of knee fullness. This type of damage triggers local biological and mechanical responses in the meniscus and joint tissues $[20,29]$. A normal meniscus may suffer acute tearing creating trauma, or degenerative tearing after abnormal meniscal loading. Traumatic tears are usually found in those 10-40 years of age and degenerative tears in older subjects, often associated with other degenerative changes in knee cartilage and bone tissue.

Meniscal tearing is a major risk factor for the development of post-traumatic arthritis and increases, by $50 \%$, the probability of symptomatic osteoarthritis (OA) within 10-20 years of post-injury repair [26]. Such biological changes can be quantified by measuring biomarkers reflecting extracellular matrix (ECM) synthesis and degradation, and inflammation, presumably acting as surrogates of joint remodelling and disease progression $[20,27]$. The balance between matrix metalloproteinase (MMP)-mediated matrix synthesis and inhibition is crucial in terms of meniscal repair [7]. Growth factors and levels of MMPs in synovial fluid have been reported to be significant criteria for the size and progression of $\mathrm{OA}$ and meniscus injury. The joint synovial fluid provides direct physical contact with the meniscus, thereby reducing joint friction during movement [2]. MMPs contribute to the degradation of ECM components in joint tissues, triggering post-traumatic OA [22]. Tumour necrosis factor alpha (TNF- $\alpha$ ) is a 17-kDa protein produced principally by activated macrophages [1]. Following joint injury, the synovial fluid levels of the pro-inflammatory cytokines interleukin (IL)-1 and TNF- $\alpha$ become elevated, with the highest (acute) levels observed within the first $24 \mathrm{~h}$ after injury $[4,18,24,46]$. Here, we used biochemical, histopathological, and immunohistochemical methods to investigate the effects of meniscal tearing on synovial fluid cells, caused by the inflammatory response and the decrease in knee movement.

\section{MATERIALS AND METHODS}

\section{Patient}

We studied patients with meniscal tears treated in the orthopaedic clinic of the medical faculty of Dicle
University. The use of human tissues was approved by Dicle University Medicine Faculty Ethical Committee. All patients provided written informed consent. We enrolled patients who visited the Department of Orthopaedics, Medical School, Dicle University from June 2017 to January 2018 with local knee pain and/ or swelling, difficulty climbing stairs, patellar creeping, difficulties with daily living activities, local pain on palpation, and walking and running complaints.

\section{MRI protocols}

We performed preoperative magnetic resonance imaging (MRI) of 45 males (aged 35-53 years) and 35 females (aged 45-64 years) with meniscal tears. In total, 52 patients had one-sided meniscal tears and 28 patients two-sided tears. All knees were imaged with the same 1.5 T MR (Philips Achieva) scanner and an eight-channel knee coil on each system. All patients were evaluated using the same MRI protocol. Standard knee MRI included coronal T1 sequences, sagittal $\mathrm{T} 2$ sequences, and sagittal-coronal $\mathrm{T} 2$ fat-suppressed sequences.

\section{Synovial fluid sampling procedure}

With each patient in the supine position, a minimum of $5 \mathrm{~mL}$ of synovial fluid was aspirated from the lateral suprapatellar pouch of the affected knee via an injector. Blood samples were also collected. The synovial fluid was subjected to high-speed centrifugation, the supernatant was discarded, and 10\% (v/v) neutral formalin was added (pellet:formalin volume ratio, 1:3). After $2 \mathrm{~h}$ of fixation, the clear bright supernatant was discarded and the tube was inverted on filter paper to allow excess fluid to drain. The pellet was then placed on filter paper using a spatula and eosin stain solution was added using a Pasteur pipette. After the cell aggregate developed a red colour, it was wrapped in filter paper and placed in a cassette, which was then stored in a fixation box for tissue processing. The cells were examined following Harris haematoxylin and eosin (H\&E) staining. The synovial fluid was also immunostained and examined under a light microscope.

\section{Immunohistochemical staining}

Sections were placed in distilled water and washed three times for $5 \mathrm{~min}$ with phosphate-buffered saline (PBS) (catalogue no. 10010023; Thermo Fisher Scientific, Fremont, CA, USA). Antigen retrieval was performed in a microwave oven (Bosch, $700 \mathrm{~W}$ ) for 
$3 \mathrm{~min}$ at $90^{\circ} \mathrm{C}$ in citrate buffer $(\mathrm{pH} 6)$. The sections were washed three times for 5 min with PBS and incubated with hydrogen peroxide (catalogue no. K-40677109, 64271; Merck, Dortmund, Germany) (3 $\mathrm{mL} 30 \%[\mathrm{v} / \mathrm{v}] \mathrm{H}_{2} \mathrm{O}_{2}+27 \mathrm{~mL}$ methanol) for $20 \mathrm{~min}$. The sections were washed 3 times for 5 min with PBS and blocked with Ultra V Block (lot PHL150128; Thermo Fisher Scientific) for $8 \mathrm{~min}$. After draining, primary antibodies were directly added to the sections. The antibodies were MMP-9 (monoclonal antibody; 1:100; catalogue no. PA5-13199; Thermo Fisher Scientific) and TNF- $\alpha$ (catalogue no. PHC3015; 1:100; Thermo Fisher Scientific) followed by incubation overnight at $4^{\circ} \mathrm{C}$. The sections were washed 3 times for $5 \mathrm{~min}$ with PBS and incubated with biotinylated secondary antibody (lot PHL150128; Thermo Fisher Scientific) for 14 min. After washing with PBS, streptavidin peroxidase (lot PHL150128; Thermo Fisher Scientific) was added for $15 \mathrm{~min}$ followed by washing 3 times for $5 \mathrm{~min}$ with PBS and the addition of DAB (lot HD36221; Thermo Fisher Scientific) for up to $10 \mathrm{~min}$. As the reaction developed, the slides were placed in PBS, counterstained with Harris haematoxylin (haematoxylin and eosin, $\mathrm{H} \& \mathrm{E})$ for $45 \mathrm{~s}$, dehydrated through baths of ascending alcohol proportions; cleared in xylene (catalogue no. HHS32; Sigma-Aldrich, St. Louis, MO, USA); mounted with Entellan (lot 107961; Sigma-Aldrich), and examined using an Olympus $\mathrm{BH}-2$ light microscope.

\section{Western blotting}

The protein expression levels of TNF- $\alpha$ and MMP-9 were examined by Western blotting. Briefly, proteins were extracted from synovial tissues [47], separated on $10-12 \%$ SDS-PAGE gels ( $40 \mathrm{mg} / \mathrm{lane}$ ) and then transferred to nitrocellulose membrane (Bio-Rad, Hercules, CA). The membranes were blocked with $5 \%$ non-fat milk in TBST buffer $(10 \mathrm{mmol} / \mathrm{L}$ Tris- $\mathrm{HCl}$, $0.15 \mathrm{~mol} / \mathrm{L} \mathrm{NaCl}$, and $0.05 \%$ Tween 20, pH 7.1) for $2 \mathrm{~h}$ and incubated with primary antibodies overnight at $4^{\circ} \mathrm{C}$. Primary antibodies used here were monoclonal human antibodies against MMP-9 (1:1000 dilution; Cell Signaling Technology, Boston, MA), and TNF- $\alpha$ (1:1000 dilution; Cell Signaling Technology, Boston, MA). After extensive washing with TBST buffer, the blotted membranes were then incubated for $1 \mathrm{~h}$ at room temperature with an HRP-conjugated secondary antibody directed against rabbit IgG (1:2,000; Cell Signaling Technology, Boston, MA). The proteins were detected using an enhanced chemiluminescence system (ECL kit, Pierce Biotechnology, Beijing, China) and

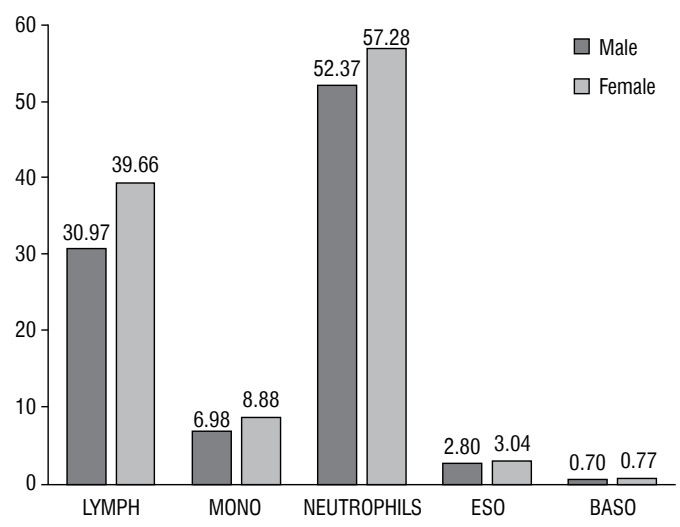

Graph 1. Blood cell counts in male and female patients; LYMPH lymphocytes; MONO - monocytes; ESO — eosonophils; BASO — basophils.

captured on light sensitive X-ray film (AGFA, Belgium). Tissue densities were detected using ImageJ software.

\section{Statistical analysis}

IBM SPSS software ver. 21.0 for Windows was used for all analyses. Data are presented as the mean \pm standard deviation. Categorical variables are shown as numbers with percentages (\%). Between-gender comparisons were made with the aid of the MannWhitney U-test. All hypotheses were bidirectional and a $p$-value $<0.05$ was considered to reflect statistical significance.

\section{RESULTS}

\section{Blood and MRI findings}

The lymphocyte counts were $30.97 \pm 3.28$ in males and $39.66 \pm 1.59$ in females, and the monocyte counts were $6.98 \pm 0.73$ in males and $8.88 \pm$ \pm 0.65 in females. The mean neutrophil count was $52.37 \pm 3.33$ in males and $57.28 \pm 5.01$ in females. The genders differed significantly in terms of lymphocyte, monocyte, and neutrophil numbers (all p-values $<0.001$, Graph 1). In the male blood samples, the eosinophil number was $2.80 \pm 0.37$ and that of females was $3.04 \pm 0.24$; the basophil counts were $0.70 \pm 0.24$ and $0.77 \pm 0.21$, respectively, and the differences were not significant (both $p$-values $>0.05$, Graph 1).

Magnetic resonance imaging of a 35-year-old female patient revealed a degenerative horizontal tear of the medial meniscus rim of the left knee (Fig. 1a). Imaging of the posterior horn of the same patient revealed that the rupture was oval in shape (Fig. 1b) and dislocated. MRI of the left knee revealed a degen- 


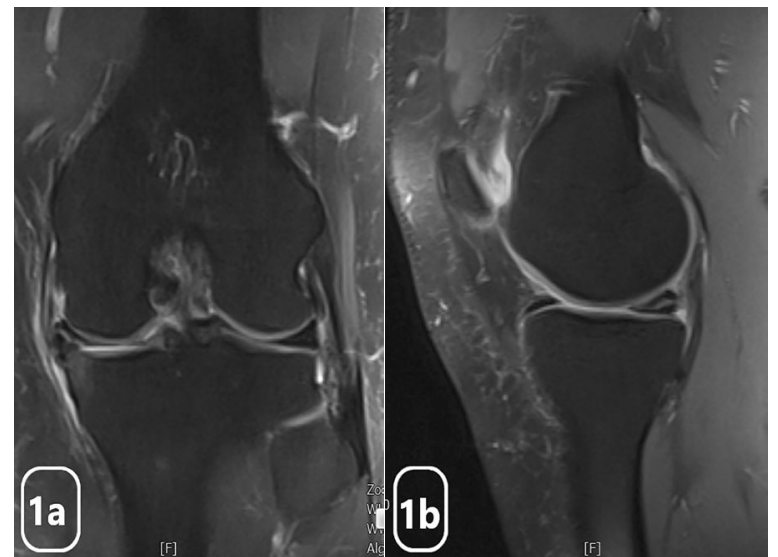

Figure 1. a. A coronal T2 weighted magnetic resonance imaging (MRI) showing a degenerative horizontal tear of the medial meniscus rim of the left knee (a 35-year-old female patient); $\mathbf{b}$. A sagittal T2 weighted MRI showing oval-shaped rupture (a 35-year-old female patient).

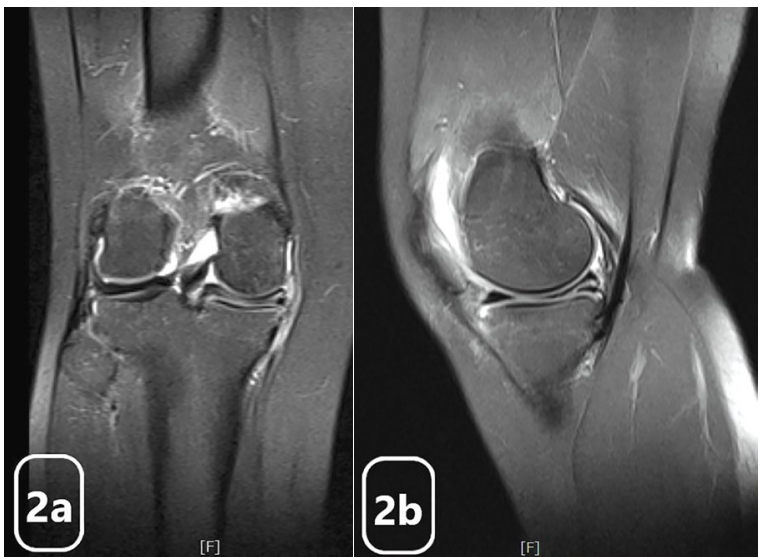

Figure 2. a. A coronal T2 weighted magnetic resonance imaging (MRI) showing a degenerative horizontal tear (caused by trauma) in the medial meniscal region (a 19-year-old female patient); b. A sagittal T2 weighted MRI showing horizontal rupture of the posterior horn (a 19-year-old female patient).

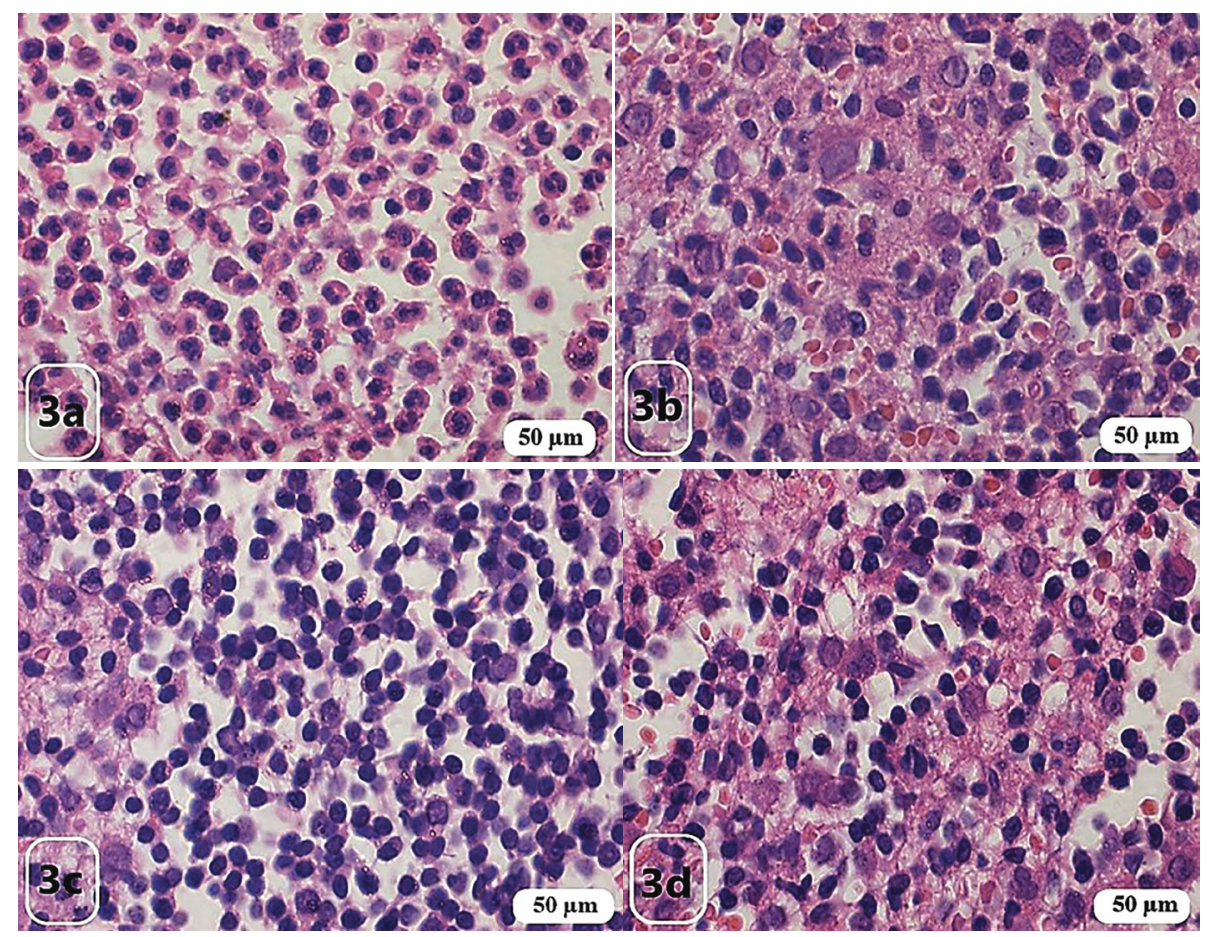

Figure 3. a. Haematoxylin and eosin (H\&E) staining. The lymphocytes were dense, neutrophils were absent, and no chromatin bridges were apparent between polymorphic nuclei. Scale bar $=50 \mu \mathrm{m} ; \mathbf{b}$. H\&E staining. Plasma cells were prominent, fibroblasts were hyperplastic, and fibroblast and erythrocyte numbers were increased. Scale bar $=50 \mu \mathrm{m} ; \mathbf{c}$. H\&E staining. Lymphocytes of various sizes increased in number. Scale bar $=50 \mu \mathrm{m}$; d. H\&E staining. Plasma cells were prominent, as were fibroblasts, and scattered hyperplastic erythrocytes were evident. Scale bar $=50 \mu \mathrm{m}$.

erative horizontal tear (caused by trauma) in the medial meniscal region of a 19-year-old female patient (Fig. 2a), and horizontal rupture of the posterior horn (Fig. 2b).

\section{Histological findings}

The increased levels of abnormal cells in the synovial fluid reflected the severity of meniscal tearing. On microscopic examination of synovial fluid cells from females with meniscal ruptures, the lymphocytes were dense and the neutrophils markedly polynucleated, but no nuclear chromatin bridges were apparent. Plasma cells were evident; the fibroblasts exhibited hyperplasia; and erythrocyte numbers were high (reflecting a hematoma) (Fig. 3a, b). On microscopic 
examination of the synovial fluid cells of males, increased numbers of lymphocytes (of various sizes) were noted. Plasma cells were evident, and the fibroblasts were hyperplastic. Plasma cells are generally abundant in regions of chronic inflammation. The erythrocytes were scattered (Fig. 3c, d).

\section{Immunohistochemical findings}

Immunohistochemical examination revealed that MMP-9 expression was increased in lymphocytes, fibroblasts, and neutrophils of both males and females, and plasma cells of females (Fig. 4a, b). Following inflammation, MMP-9 is thought to modulate matrix degradation, collagen synthesis, and angiogenic development (Fig. 4c, d). In females, TNF- $\alpha$ was expressed by neutrophils, lymphocytes, and phagocytic monocytes (Fig. 5a, b). Notably, TNF- $\alpha$ expression was increased in polymorphic nucleated cells, plasma cells, fibroblasts, and neutrophils of males, and in some lymphocytes (Fig. 5c, d).

\section{Western blot findings}

In a total of 80 patients with meniscus tears, MMP-9 and TNF- $\alpha$ expression in synovial cells of 4 patients were evaluated by Western blot analysis. The picture showing total protein weight and expression of TNF- $\alpha$ and MMP-9 were included in the study (Fig. 6).

\section{DISCUSSION}

In this study, meniscus tears which were caused by trauma in 80 patients were determined by MRI and the MMP-9 and TNF- $\alpha$ expressions in synovial fluid samples were examined by immunohistopathology and Western blot analysis. This study found that the expression of these proteins in synovial fluid samples increased immunohistochemically. In parallel with this increase in expression, it was determined that the molecular weights of these proteins increased in the Western blot analysis.

Clinically, meniscus tears have been reported to be both acute and chronic forms [38]. Anatomically, the posterior horns of the medial and lateral menisci transmit more load than the anterior horns while the leg is at $90^{\circ}$ flexion [10]. For this reason, posterior medial meniscus tears were the main focus of the studies [19, 35]. Meniscal damage increases the risk of knee OA. Meniscal surgery following radial and oblique tearing of the middle and posterior third of the medial meniscus can significantly increase cartilage tension in the tibial and femoral condyles, possibly because the extent of tissue resorption following radial or oblique tearing may be less than that after longitudinal tearing. Radial tearing will cause more damage to peripheral fibrils running from the inner to outer surface $[6,15,16,37,40]$. MRI affords a $90-95 \%$ diagnostic success rate, although MRI data should be combined with clinical findings $[12,44]$. We showed a 35 -year-old male patient with a degenerative horizontal tear of the medial meniscus rim of the left knee (Fig. 1). The MRI also revealed degenerative horizontal rupture (a medial meniscal tear) in the left knee of a 19-year-old female patient after trauma (Fig. 2). Acute inflammation is usually of sudden onset, developing over minutes or hours; the classical symptoms are heat, pain, redness, and swelling. Chronic inflammation develops over a longer period of time, and may persist for days, weeks, or months [28].

Neutrophils have been found to be the most inflammatory cells in patients with acute synovitis. On the other hand, it has been reported that many macrophages are frequently accompanied by lymphocytic infiltrates in OA chronic synovitis patients [23]. Meniscal damage (caused especially by degenerative and traumatic tearing) is accompanied by both acute and chronic inflammation. Such a response is noted following rupture of the anterior cruciate ligament $(\mathrm{ACL})$, traumatic meniscus tearing, and in those with premature OA [9]. Shortly after ACL rupture, the joint levels of inflammatory cytokines, particularly IL-1 and TNF- $\alpha$, rise [21]. Several parameters including obesity, diurnal rhythm, diet, medications, sample collection/ storage procedures, time of sample collection, physical activity level, trauma, and gender affect the measured levels of these cytokines [14, 39, 48].

High levels of TNF- $\alpha$ and IL- 6 in traumatic areas indicate the level of cartilage damage and the presence of a local inflammatory response that triggers early knee OA [32]. Cuellar et al. [8] reported a correlation between synovial fluid levels of IL- 6 and the pain score in patients with $\mathrm{ACL}$ tears, but no effect on the level of TNF- $\alpha$ was apparent. By contrast, Orita et al. [33] found a positive correlation between the synovial fluid TNF- $\alpha$ level and the pain score in OA patients. In patients with meniscal tears, elevated levels of cytokines in synovial cells and increased OA activity change the osteoclastic numbers and cartilage tissue morphology. The levels of soluble TNF receptors in the sera of OA patients correlated positively with pain, joint stiffness, and increased radiographic severity of disease [41]. Aging is correlated with increased systemic inflammation and can trigger mitochondrial dysfunction and an inability to eliminate oxidatively damaged proteins 

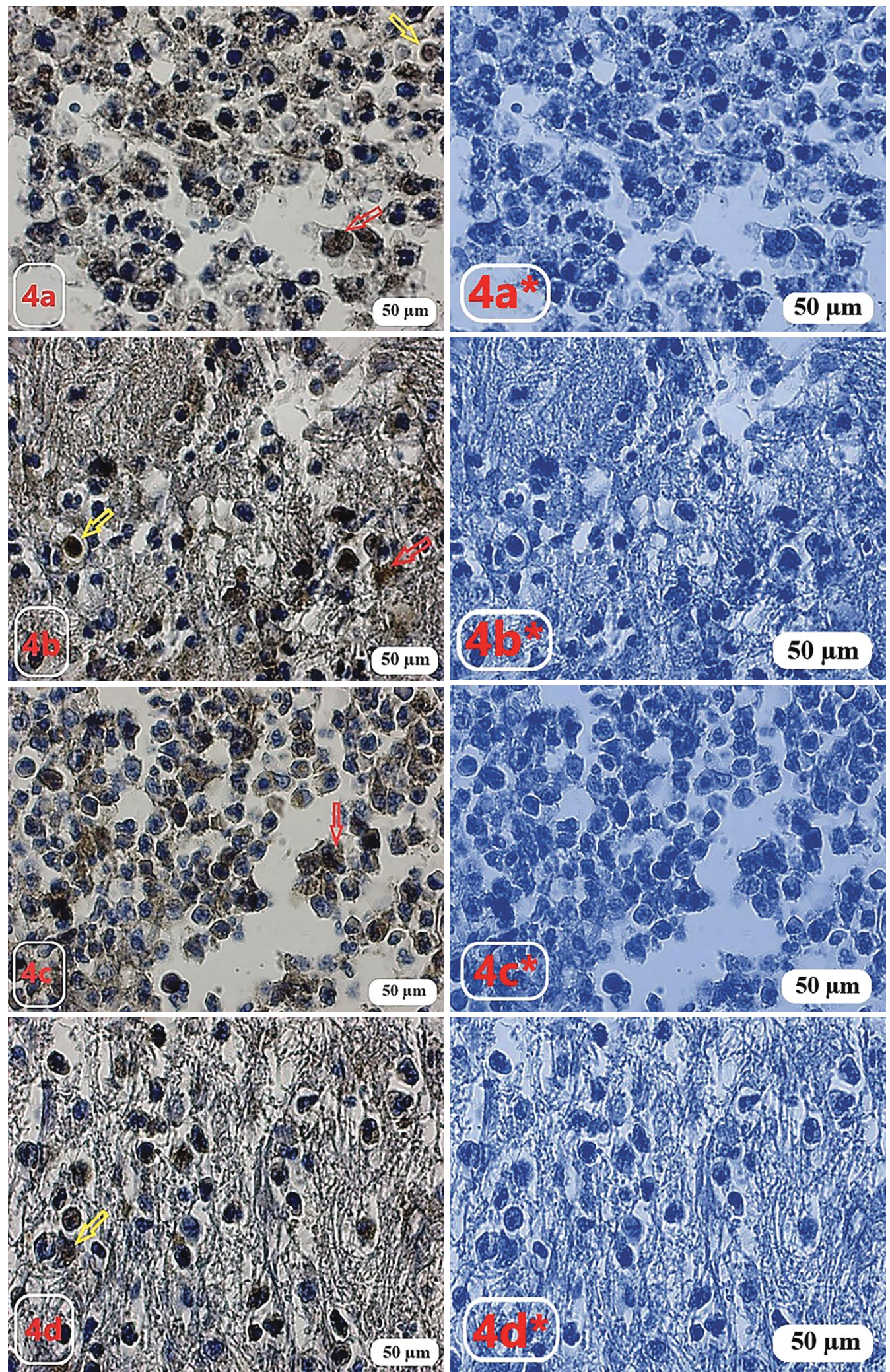

Figure 4. a. Matrix metalloproteinase 9 (MMP-9) immunostaining. Increased MMP-9 expression in lymphocytes (yellow arrow), plasma cells (red arrow), fibroblasts, and neutrophils of females. Scale bar $=50 \mu \mathrm{m} ; \mathbf{a}^{*}$. Negative control, haematoxylene staining. Scale bar $=50 \mu \mathrm{m}$; b. MMP-9 immunostaining. MMP-9 expression in lymphocytes (yellow arrow), fibroblasts (red arrow) and neutrophils of males. Scale bar $=$ $50 \mu \mathrm{m}$. $\mathbf{b}^{*}$. Negative control, haematoxylene staining. Scale bar $=50 \mu \mathrm{m} ; \mathbf{c}$. MMP-9 immunostaining. MMP-9 expression in plasma cells (red arrow) and neutrophils. Scale bar $=50 \mu \mathrm{m} ; \mathbf{c}^{*}$. Negative control, haematoxylene staining. Scale bar $=50 \mu \mathrm{m} ; \mathbf{d}$. MMP-9 immunostaining. MMP-9 expression in hyperplastic fibroblasts (yellow arrow). Scale bar $=50 \mu \mathrm{m} ; \mathbf{d}^{*}$. Negative control, haematoxylene staining. Scale bar $=50 \mu \mathrm{m}$. 

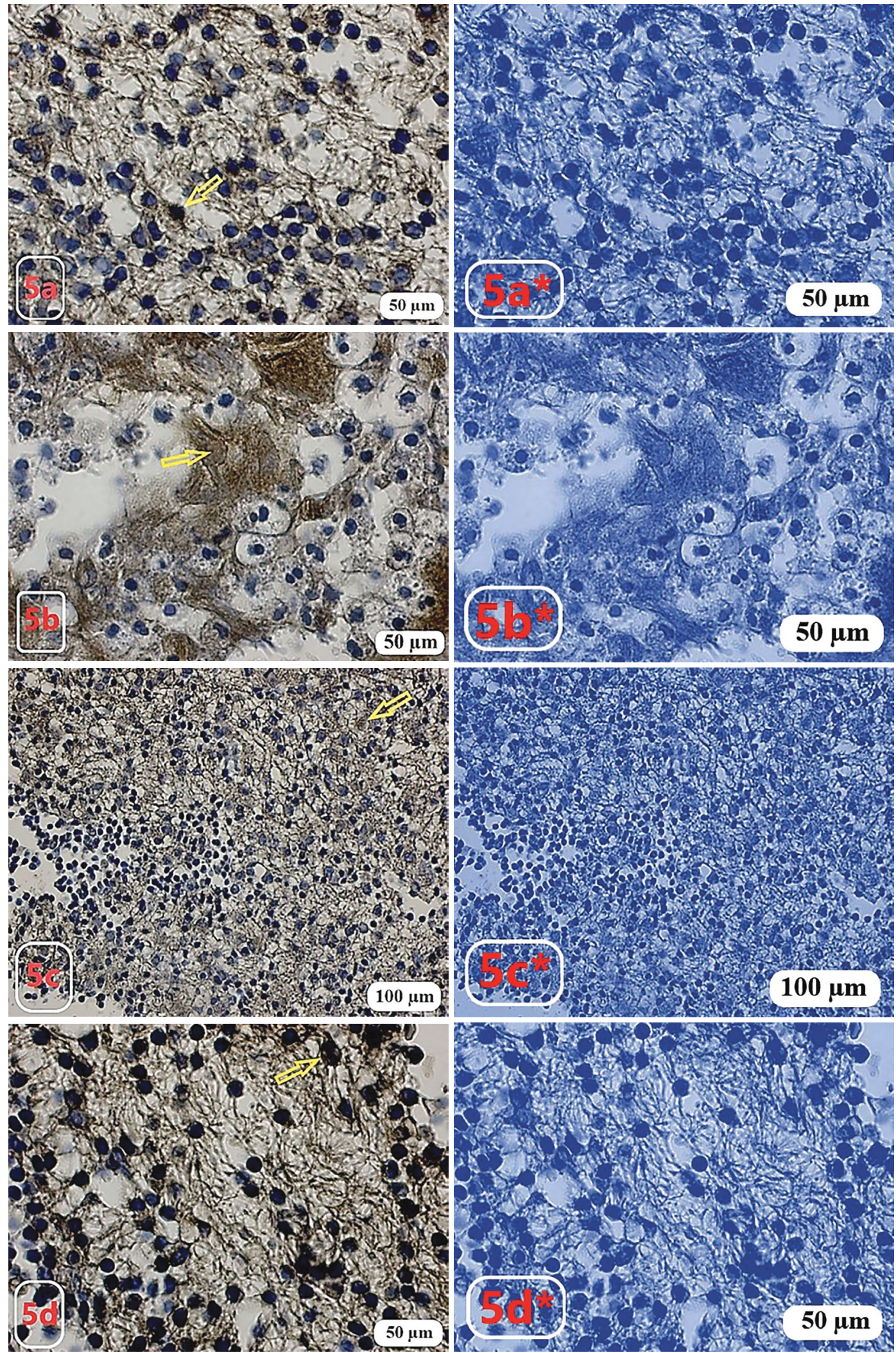

Figure 5. a. Tumour necrosis factor alpha (TNF- $\alpha$ ) immunostaining. TNF- $\alpha$ expression in neutrophils, lymphocytes (yellow arrow), and phagocytic monocytes. Scale bar $=50 \mu \mathrm{m} ; 5 \mathbf{a}^{*}$. Negative control, haematoxylene staining. Scale bar $=50 \mu \mathrm{m} ; \mathbf{b}$. TNF- $\alpha$ immunostaining. Increased TNF- $\alpha$ expression in polymorphic nuclear cells (yellow arrow). Scale bar $=50 \mu \mathrm{m} ; \mathbf{b}^{*}$. Negative control, haematoxylene staining. Scale bar $=50 \mu \mathrm{m}$; c. TNF- $\alpha$ immunostaining. TNF- $\alpha$ expression in plasma cells (yellow arrow), and neutrophils of males. Scale bar $=100 \mu \mathrm{m} ; \mathbf{c}^{*}$. Negative control, haematoxylene staining. Scale bar $=100 \mu \mathrm{m}$; d. TNF- $\alpha$ immunostaining. TNF- $\alpha$ expression in fibroblasts (yellow arrow) and some lymphocytes. Scale bar $=50 \mu \mathrm{m} ; \mathbf{5 d}^{*}$. Negative control, haematoxylene staining. Scale bar $=50 \mu \mathrm{m}$. 


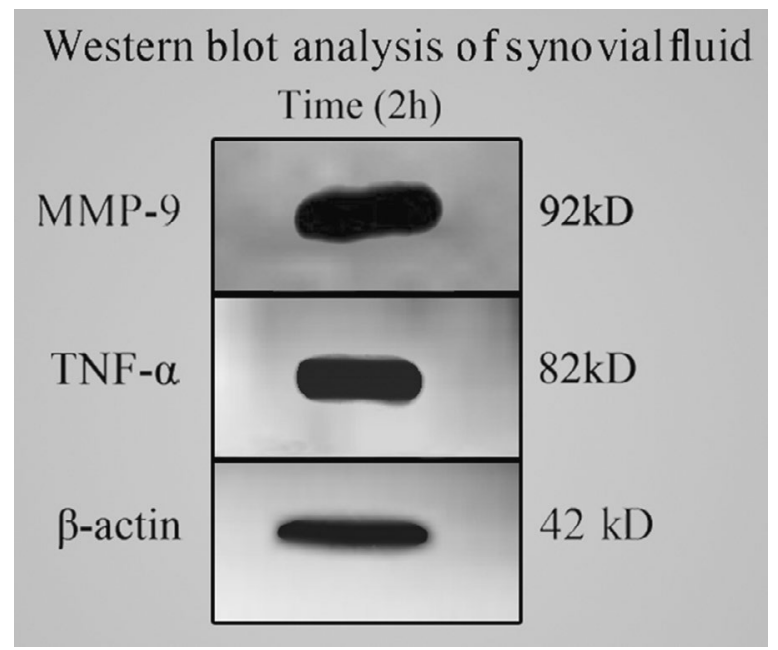

Figure 6. The expression of tumour necrosis factor alpha (TNF- $\alpha$ ) and matrix metalloproteinase 9 (MMP-9) on synovial tissue was dramatically increased in patients with meniscal tears. Equal amounts of total proteins were run on the gel and analysed by Western blotting using anti-TNF- $\alpha$, anti-MMP- 9 and anti- $\beta$-actin antibodies. $\beta$-actin was used as a loading control. The position of molecular weight markers $(k D)$ is shown $(n=4)$.

from chondrocytes, in turn causing cell senescence and increased production of inflammatory cytokines $[3,25]$. Rutgers et al. [42] concluded that inhibition of $40 \mathrm{ng} / \mathrm{mL}$ TNF- $\alpha$ via intravenous injection enhanced cartilage metabolism. We found that TNF- $\alpha$ levels were increased in meniscal tears, suggesting that TNF- $\alpha$ contributes to the pathogenesis of joint damage in chronic $\mathrm{OA}$ and rheumatic diseases, perhaps triggering cartilage and bone resorption.

Normal meniscal cells exhibited a marked increase in MMP expression $6 \mathrm{~h}$ after stimulation, but OA cells responded less rapidly, perhaps due to differences in receptor concentrations or relevant inflammatory pathways [45]. MMPs degrade and process many components of the ECM, including the basement membrane, and are thought to be important in terms of tumour spread and angiogenesis [31, 34]. The ECM is a complex mesh of structural and signalling molecules affording dynamic support to cells and tissues and modulating cell behaviour [30, 36]. MMP-9 is a proteolytic enzyme that plays a key role in tissue remodelling during pathological processes, initiating ECM degradation. And, we found that MMP-9 expression was increased in the lymphocytes and plasma cells of both male and female patients, inducing chronic inflammation and ECM deterioration. In addition, MMP-9 expression in fibroblasts may affect the synthesis of collagen fibres.

Liu et al. [24] observed that the total MMP activity in synovial fluid correlated negatively with the levels of MMP-3, MMP-9, and MMP-10 in patients with meniscal tears, indicating that these enzymes do not increase overall MMP activity. The levels of MMP expression in synovial cells have been reported to be modulated by different extracellular signals in patients with rheumatoid arthritis. Synovial fibroblasts directly stimulate the expression of both inflammatory cytokines and disease-associated MMPs [43].

There are important limitations to be considered in this immunohistochemical study. Increase in MMP-9 $[5,17]$ and TNF- $\alpha[5]$ expressions in patients with meniscal tear has been shown only in mRNA levels in a limited number of studies. In this study, the increase in expression of these proteins is shown immunohistochemically in patients with meniscus tear. In parallel with the increase in MMP-9 and TNF- $\alpha$ expressions, it has been shown that the molecule levels of these proteins increased by western blot analysis. In addition, we observed that MMP activity was increased in synovial fluid cells of meniscal tear patients exhibiting cartilage tension. After tearing, synovial cells act on the adjacent cartilage matrix, inducing tension by hyperactivating matrix-degrading enzymes. Thus, interactions among tissues trigger prolonged episodes of signalling.

\section{CONCLUSIONS}

We found that the increased fluid levels in inflamed joints with meniscal tears, and the inflammation per se, disrupted the cartilage matrix. As increases in the levels of TNF- $\alpha$ and MMP-9 disrupted cells that synthesize such materials (i.e., fibroblasts), it is possible that anti-TNF- $\alpha$ treatment would prevent meniscal tearing.

\section{REFERENCES}

1. Aggarwal BB, Gupta SC, Sung B. Curcumin: an orally bioavailable blocker of TNF and other pro-inflammatory biomarkers. Br J Pharmacol. 2013; 169(8): 1672-1692, doi: 10.1111/bph.12131, indexed in Pubmed: 23425071.

2. Balakrishnan L, Nirujogi RS, Ahmad S, et al. Proteomic analysis of human osteoarthritis synovial fluid. Clin Proteomics. 2014; 11(1): 6, doi: 10.1186/1559-0275-11-6, indexed in Pubmed: 24533825.

3. Berenbaum F. Osteoarthritis as an inflammatory disease (osteoarthritis is not osteoarthrosis!). Osteoarthr Cartil. 2013; 21(1): 16-21, doi: 10.1016/j.joca.2012.11.012, indexed in Pubmed: 23194896.

4. Bigoni $M$, Sacerdote $P$, Turati $M$, et al. Acute and late changes in intraarticular cytokine levels following anterior cruciate ligament injury. J Orthop Res. 2013; 31(2): 315-321, doi: 10.1002/jor.22208, indexed in Pubmed: 22886741.

5. Brophy RH, Rai MF, Zhang Z, et al. Molecular analysis of age and sex-related gene expression in meniscal tears with 
and without a concomitant anterior cruciate ligament tear. J Bone Joint Surg Am. 2012; 94(5): 385-393, doi: 10.2106/ JBJS.K.00919, indexed in Pubmed: 22362494.

6. Brophy RH, Wojahn RD, Lillegraven O, et al. Outcomes of Arthroscopic Posterior Medial Meniscus Root Repair: Association With Body Mass Index. J Am Acad Orthop Surg. 2019; 27(3): 104-111, doi: 10.5435/JAAOS-D-17-00065, indexed in Pubmed: 30192250.

7. Buma P, Ramrattan NN, van Tienen TG, et al. Tissue engineering of the meniscus. Biomaterials. 2004; 25(9): 1523-1532, indexed in Pubmed: 14697855.

8. Cuellar VG, Cuellar JM, Golish SR, et al. Cytokine profiling in acute anterior cruciate ligament injury. Arthroscopy. 2010; 26(10): 1296-1301, doi: 10.1016/j.arthro.2010.02.011, indexed in Pubmed: 20887928.

9. Englund M, Roemer FW, Hayashi D, et al. The role of the meniscus in knee osteoarthritis: a cause or consequence? Radiol Clin North Am. 2009; 47(4): 703-712, doi: 10.1016/j. rcl.2009.03.003, indexed in Pubmed: 19631077.

10. Fox AJS, Bedi A, Rodeo SA. The basic science of human knee menisci: structure, composition, and function. Sports Health. 2012; 4(4): 340-351, doi: 10.1177/1941738111429419, indexed in Pubmed: 23016106.

11. Fox AJS, Wanivenhaus F, Burge AJ, et al. The human meniscus: a review of anatomy, function, injury, and advances in treatment. Clin Anat. 2015; 28(2): 269-287, doi: 10.1002/ ca.22456, indexed in Pubmed: 25125315.

12. Ghosh N, Kruse D, Subeh M, et al. Comparing Point-ofcare-ultrasound (POCUS) to MRI for the Diagnosis of Medial Compartment Knee Injuries. J Med Ultrasound. 2017; 25(3): 167-172, doi: 10.1016/j.jmu.2017.06.004, indexed in Pubmed: 30065483.

13. Gray JC. Neural and vascular anatomy of the menisci of the human knee. J Orthop Sports Phys Ther. 1999; 29(1): 23-30, doi: 10.2519/jospt.1999.29.1.23, indexed in Pubmed: 10100118.

14. Haack M, Pollmächer T, Mullington JM. Diurnal and sleep-wake dependent variations of soluble TNF- and IL-2 receptors in healthy volunteers. Brain Behav Immun. 2004; 18(4): 361-367, doi: 10.1016/j.bbi.2003.12.009, indexed in Pubmed: 15157953.

15. Hart HF, Crossley KM, Felson D, et al. Relation of meniscus pathology to prevalence and worsening of patellofemoral joint osteoarthritis: the Multicenter Osteoarthritis Study. Osteoarthr Cartil. 2018; 26(7): 912-919, doi: 10.1016/j. joca.2017.11.017, indexed in Pubmed: 29427724.

16. Hart HF, Crossley KM, Hunt MA. Gait patterns, symptoms, and function in patients with isolated tibiofemoral osteoarthritis and combined tibiofemoral and patellofemoral osteoarthritis. J Orthop Res. 2018; 36(6): 1666-1672, doi: 10.1002/jor.23805, indexed in Pubmed: 29139573.

17. Hsieh YS, Yang SF, Chu SC, et al. Expression changes of gelatinases in human osteoarthritic knees and arthroscopic debridement. Arthroscopy. 2004; 20(5): 482-488, doi: 10.1016/j.arthro.2004.03.010, indexed in Pubmed: 15122138.

18. Irie $\mathrm{K}$, Uchiyama E, Iwaso $\mathrm{H}$. Intraarticular inflammatory cytokines in acute anterior cruciate ligament injured knee. Knee. 2003; 10(1): 93-96, indexed in Pubmed: 12649034.

19. Jones AO, Houang MTW, Low RS, et al. Medial meniscus posterior root attachment injury and degeneration:
MRI findings. Australas Radiol. 2006; 50(4): 306-313, doi: 10.1111/j.1440-1673.2006.01586.x, indexed in Pubmed: 16884414 .

20. Koryem H, Wanas M, Rizk M, et al. Evaluation of early changes of cartilage biomarkers following arthroscopic meniscectomy in young Egyptian adults. Alexandria J Med. 2019; 51(3): 191-197, doi: 10.1016/j.ajme.2014.06.005.

21. Lawrence JT, Birmingham J, Toth AP. Emerging ideas: prevention of posttraumatic arthritis through interleukin-1 and tumor necrosis factor-alpha inhibition. Clin Orthop Relat Res. 2011; 469(12): 3522-3526, doi: 10.1007/ s11999-010-1699-4, indexed in Pubmed: 21161742.

22. Lewis JS, Hembree WC, Furman BD, et al. Acute joint pathology and synovial inflammation is associated with increased intra-articular fracture severity in the mouse knee. Osteoarthr Cartil. 2011; 19(7): 864-873, doi: 10.1016/j. joca.2011.04.011, indexed in Pubmed: 21619936.

23. Lingen MW. Role of leukocytes and endothelial cells in the development of angiogenesis in inflammation and wound healing. Arch Pathol Lab Med. 2001; 125(1): 67-71, doi: 10.1043/0003-9985(2001)125<0067:ROLAEC>2.0. CO;2, indexed in Pubmed: 11151055.

24. Liu B, Goode AP, Carter TE, et al. Matrix metalloproteinase activity and prostaglandin E2 are elevated in the synovial fluid of meniscus tear patients. Connect Tissue Res. 2017; 58(3-4): 305-316, doi: 10.1080/03008207.2016.1256391, indexed in Pubmed: 27813662.

25. Loeser RF. The effects of aging on the development of osteoarthritis. HSS J. 2012; 8(1): 18-19, doi: 10.1007/ s11420-011-9237-9, indexed in Pubmed: 23372520.

26. Lohmander LS, Englund PM, Dahl LL, et al. The long-term consequence of anterior cruciate ligament and meniscus injuries: osteoarthritis. Am J Sports Med. 2007; 35(10): 1756-1769, doi: 10.1177/0363546507307396, indexed in Pubmed: 17761605.

27. Lotz M, Martel-Pelletier J, Christiansen C, et al. Value of biomarkers in osteoarthritis: current status and perspectives. Ann Rheum Dis. 2013; 72(11): 1756-1763, doi: 10.1136/annrheumdis-2013-203726, indexed in Pubmed: 23897772.

28. Lotz MK, Kraus VB. New developments in osteoarthritis. Posttraumatic osteoarthritis: pathogenesis and pharmacological treatment options. Arthritis Res Ther. 2010; 12(3): 211, doi: 10.1186/ar3046, indexed in Pubmed: 20602810.

29. McNulty AL, Rothfusz NE, Leddy HA, et al. Synovial fluid concentrations and relative potency of interleukin- 1 alpha and beta in cartilage and meniscus degradation. J Orthop Res. 2013; 31(7): 1039-1045, doi: 10.1002/jor.22334, indexed in Pubmed: 23483596.

30. Mott JD, Werb Z. Regulation of matrix biology by matrix metalloproteinases. Curr Opin Cell Biol. 2004; 16(5): 558-564, doi: 10.1016/j.ceb.2004.07.010, indexed in Pubmed: 15363807.

31. Nagase H, Woessner JF. Matrix metalloproteinases. J Biol Chem. 1999; 274(31): 21491-21494, doi: 10.1074/ jbc.274.31.21491, indexed in Pubmed: 10419448.

32. Ogura T, Suzuki M, Sakuma $Y$, et al. Differences in levels of inflammatory mediators in meniscal and synovial tissue of patients with meniscal lesions. J Exp Orthop. 2016; 3(1): 7, doi: 10.1186/s40634-016-0041-9, indexed in Pubmed: 26915007. 
33. Orita S, Koshi T, Mitsuka T, et al. Associations between proinflammatory cytokines in the synovial fluid and radiographic grading and pain-related scores in 47 consecutive patients with osteoarthritis of the knee. BMC Musculoskelet Disord. 2011; 12: 144, doi: 10.1186/1471-2474-12-144, indexed in Pubmed: 21714933.

34. Overall CM. Molecular determinants of metalloproteinase substrate specificity: matrix metalloproteinase substrate binding domains, modules, and exosites. Mol Biotechnol. 2002; 22(1): 51-86, doi: 10.1385/MB:22:1:051, indexed in Pubmed: 12353914.

35. Ozkoc G, Circi E, Gonc U, et al. Radial tears in the root of the posterior horn of the medial meniscus. Knee Surg Sports Traumatol Arthrosc. 2008; 16(9): 849-854, doi: 10.1007/ s00167-008-0569-z, indexed in Pubmed: 18536902.

36. Page-McCaw A, Ewald AJ, Werb Z. Matrix metalloproteinases and the regulation of tissue remodelling. Nat Rev Mol Cell Biol. 2007; 8(3): 221-233, doi: 10.1038/nrm2125, indexed in Pubmed: 17318226.

37. Papalia R, Papalia G, Russo F, et al. Meniscal extrusion as booster of osteoarthritis. J Biol Regul Homeost Agents. 2017; 31 (4 Suppl 2): 33-44, indexed in Pubmed: 29202561.

38. Papalia R, Vasta S, Franceschi F, et al. Meniscal root tears: from basic science to ultimate surgery. Br Med Bull. 2013; 106: 91-115, doi: 10.1093/bmb/ldt002, indexed in Pubmed: 23377537.

39. Payette $C$, Blackburn $P$, Lamarche B, et al. Sex differences in postprandial plasma tumor necrosis factor-alpha, interleukin-6, and C-reactive protein concentrations. Metabolism. 2009; 58(11): 1593-1601, doi: 10.1016/j. metabol.2009.05.011, indexed in Pubmed: 19604525.

40. Peña E, Calvo B, Martínez MA, et al. Finite element analysis of the effect of meniscal tears and meniscectomies on human knee biomechanics. Clin Biomech. 2005; 20(5): 498-507, doi: 10.1016/j.clinbiomech.2005.01.009, indexed in Pubmed: 15836937.

41. Penninx BW, Abbas $H$, Ambrosius $W$, et al. Inflammatory markers and physical function among older adults with knee osteoarthritis. J Rheumatol. 2004; 31(10): 2027-2031, indexed in Pubmed: 15468370.

42. Rutgers M, Saris DBF, Dhert WJA, et al. Cytokine profile of autologous conditioned serum for treatment of osteoarthritis, in vitro effects on cartilage metabolism and intra-articular levels after injection. Arthritis Res Ther. 2010; 12(3): R114, doi: 10.1186/ar3050, indexed in Pubmed: 20537160.

43. Scanzello CR, Goldring SR. The role of synovitis in osteoarthritis pathogenesis. Bone. 2012; 51(2): 249-257, doi: 10.1016/j.bone.2012.02.012, indexed in Pubmed: 22387238.

44. Sharon Tan SH, Kripesh A, Chan CX, et al. Gender differences in intra-articular and extra-articular injuries associated with acute anterior cruciate ligament ruptures. J Knee Surg. 2018 [Epub ahead of print], doi: 10.1055/s-00381666828, indexed in Pubmed: 30068011

45. Stone AV, Loeser RF, Vanderman KS, et al. Pro-inflammatory stimulation of meniscus cells increases production of matrix metalloproteinases and additional catabolic factors involved in osteoarthritis pathogenesis. Osteoarthr Cartil. 2014; 22(2): 264-274, doi: 10.1016/j.joca.2013.11.002, indexed in Pubmed: 24315792.

46. Swärd $P$, Frobell R, Englund $M$, et al. Cartilage and bone markers and inflammatory cytokines are increased in synovial fluid in the acute phase of knee injury (hemarthrosis) - a cross-sectional analysis. Osteoarthr Cartil. 2012; 20(11): 1302-1308, doi: 10.1016/j.joca.2012.07.021, indexed in Pubmed: 22874525.

47. Tsai SH, Liang YC, Chen L, et al. Arsenite stimulates cyclooxygenase-2 expression through activating IkappaB kinase and nuclear factor kappaB in primary and ECV304 endothelial cells. J Cell Biochem. 2002; 84(4): 750-758, indexed in Pubmed: 11835400.

48. Zhou X, Fragala MS, McElhaney JE, et al. Conceptual and methodological issues relevant to cytokine and inflammatory marker measurements in clinical research. Curr Opin Clin Nutr Metab Care. 2010; 13(5): 541-547, doi: 10.1097/ MCO.0b013e32833cf3bc, indexed in Pubmed: 20657280. 